Fermi National Accelerator Laboratory

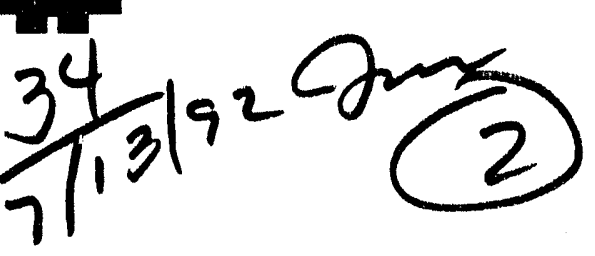

FNAL-TM- -1786

DE92 016350

\title{
Field Calculation of D0 Toroids and Comparison with Measurement
}

\author{
R. Yamada, F. Ostiguy and J. Brzezniak \\ Fermi National Accelerator Laboratory \\ P.O. Box 500, Batavia, Illinois 60510
}

DISCLAIMER

This report was prepared as an account of work sponsored by an agency of the United States Government. Neither the United States Government nor any agency thereof, nor any of their employees, makes any warranty, express or implied, or assumes any legal liability or responsibility for the accuracy, completeness, or usefulness of any information, apparatus, product, or process disclosed, or represents that its use would not infringe privately owned rights. Reference herein to any specific commercial product, process, or service by trade name, trademark, manufacturer, or otherwise does not necessarily constitute or imply its endorsement, recommendation, or favoring by the United States Government or any agency thereof. The views and opinions of authors expressed herein do not necessarily state or reflect those of the United States Government or any agency thereof.

June 1992

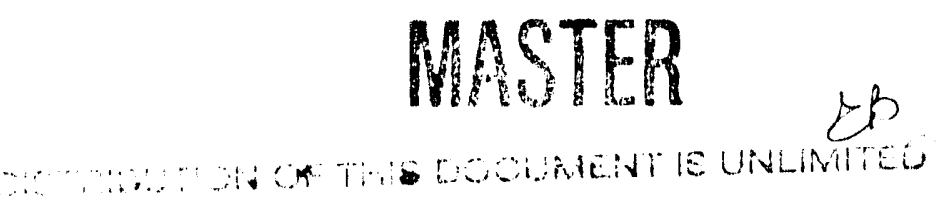




\section{Disclaimer}

This report was prepared as an account of work sponsored by an agency of the United States Government. Neither the United States Government nor any agency thereof, nor any of their employees, makes any warran'y, express or implied, or assumes any legal liability or responsibility for the accuracy, comipieteness, or usefulness of any information, apparatus, product, or process disclosed, or represents that its use would not infringe privately owned rights. Reference herein to any specific :ommercial product, process, or service by trade name, trademark, manufacturer, or otherwise, does not necessarily constitute or imply its endorsement, recommendation, or favoring by the United States Government or any agency thereof. The views and opinions of authors expressed herein do not necessarily state or reflect those of the United States Government or any agency thereof. 
D0 Note No. 1411

Field Calculation of DO Toroids and Comparison with Measurement

May 29, 1992

R. Yamada, F. Ostiguy, and J. Brzezniak

\section{INTRODUCTION}

The magnetic structure of the D0 detector is described in an earlier ieport [1]. The two-dimensional code POISSON was used for the initial design of the magnetic structures and the magnetic properties of the D0 toroids [2,3]. During the construction, the two-dimensional code ANSYS was used to perform more detailed calculations. Full three-dimensional analysis was also performed using the code TOSCA [4]. These new results are reported here and compared with measurements. In this study the magnetic flux in all toroids, CF, EF, and SAMUS is set in the same direction.

\section{B-H CURVES}

The vertical yokes of the CF toroid were made with SUREL iron recycled from an old synchrocyclotron. The horizontal yokes of $\mathrm{CF}$ and the entire EF toroids were made of distressed iron (low carbon 1006-1008 con-cast slabs) purchased from McLouth steel products Co.

To compute the field in $\mathrm{CF}$ and EF, we assumed the McLouth steel BH curve for both, since the SUREL iron is of better quality. The B-H curve, which is represented in Table I, was obtained from measurements made using small samples of McLouth steel, excited up to approximately $18 \mathrm{kG}$ and was extrapolated beyond that level using manufacturer's data for 1010 steel. For three-dimensional calculations, the B-H curve was modified to incorporate the effect of very small air gaps, which were not included in the geometry. The modified B-H curve is presented in Table II.

The SAMUS toroids were fabricated using of a mixture of Russian steel plates equivalent to American steel 1008 and 1010. The B-H curve used for calculations was obtained from measurements up to $19 \mathrm{kG}$ and extrapolated beyond that value using manufacturer's data for 1010 steel. The B-H curve used for the SAMUS toroids is presented in Table III.

All B-H curves are shown in Fig. 1 and 2 for the units of $\mathrm{A} / \mathrm{m}$ and Oersted respectively. 


\section{2-DIMENSIONAL FIELD CALCULATION}

For this series of two-dimensional field computations the finite element analysis code ANSYS was used. The solutions were obtained using a two-dimensional vector pntential formulation and the STIF13 elements. The cpu time for the simplest case of SAMUS was $3000 \mathrm{cpu} \mathrm{sec}$ with 4000 nodes in the model, and the most complicated case with the EF and SAMUS system took $15000 \mathrm{cpu}$ sec (about 4 hours) with 19000 nodes, on the VAX 8800 .

The calculated field distribution is shown with directional arrows whose length is proportional to its magnitude at the center of the element, and color coded on a color print-out. The range of the field magnitude is shown on the right side of the graph.

\subsection{CF (Run CF041092)}

The cross section of the CF toroid is shown in Figure 3, where PDT chambers and twenty unit coils inside $C F$ are shown. The $C F$ toroid is made of a stationary central beam and two side moving parts. There are $1 / 8$ inch $(3.2 \mathrm{~mm})$ gaps on both sides of the central beam and one $3 / 16$ inch $(4.8 \mathrm{~mm})$ gap at the center of the top yoke. These gaps are partially filled with stainless steel plates. The toroid is excited with twenty 10-turn unit coils at $2500 \mathrm{~A}$ per turn.

\subsubsection{Calculation}

Two-dimensional calculations for $\mathrm{CF}$ were performed using the B-H curve presented in Table I. As shown in Figure 4 symmetry is exploited and only half of the cross section is modeled. The magnetic flux distribution inside the CF yoke is shown in Figure 4, superimposed on the finite element mesh. The flux distribution is fairly uniform across the width of the yoke. Typical flux values, averaged across the width, are shown in Figure 3. The values at the top gap, the top yoke, side yoke, bottom yoke, and the central beam are 19.34, 19.54, 19.13, 19.69 and $18.68 \mathrm{kG}$ respectively. The small differences are mostly due to the different yoke thicknesses and partly due to differences in the fringing field patterns. The ratios of the inverse of the yoke width are $100.0,100.0,96.8,100.4$, and 98.0 respectively. This agrees relatively well with the corresponding field ratios: 99.0,100.0,97.9, 100.8, and 95.6. Local variations of the flux (of the order a few percent) at proximity of the coils can also be observed.

The fringing field distribution inside $\mathrm{CF}$ is shown in Figure 5. There is a strong fringing field (up to 300 Gauss) or both sides of the central beam which can be attributed mainly to the uneven distribution of the unit coils, and partly to the small air gaps.

\subsubsection{Measurernent and Comparison}


In the top gap of CF, there are five equally spaced vertical slots where a probe can be inserted to measure the field distribution across the yoke width. This was done using a Group3 Digital Teslameter. The results are shown in Figure 6. The mating surfaces in the top gap were not machined uniformly and the presence of many rough spots is obvious in this curve. The average value of the measured magnetic field in the top gap is $19.2 \mathrm{kG}$. The calculated values are $19.37 \mathrm{kG}$ at the center and $19.18 \mathrm{kG}$ at both edges. The calculated average field is $19.34 \mathrm{kG}$, a value which compares rather well to the measured average.

A fixed Group 3 probe is now installed permanently in the gap 2 and the field value can be read in the control room [5]. The excitation curve at that point was also measured and is shown in Figure 7. The agreement with the B-H curve is good. Above $15 \mathrm{kG}$, there is no noticeable hysteresis effect.

In 1989 , the flux density at the top of the vertical yoke $(\mathrm{y}=3.15 \mathrm{~m})$ was measured to be $18.4 \mathrm{kG}$ using flux loops [6]. This agrees well with the calculated value of $18.67 \mathrm{kG}$ (at $\mathrm{y}=3.1445 \mathrm{~m}$ ).

The fringing field inside $C F$ was measured along the central vertical lines at $x=0$. The results at $z=-300, G$ and $140 \mathrm{~cm}$ are shown in Figure 8 . The measurement and calculation are qualitatively in agreement. However, the calculated field value on the beam axis (at $x=y=0$ ) by 2-D ANSYS is $46 \mathrm{G}$ (in the horizontal direction), much higher than the measured value of $8 \mathrm{G}$. The discrepancy is probably due to a threedimensional effect. The calculated value by $3-D$ TOSCA is also shown in Figure 8 , which has more reasonable data near the center at $y=0$. The fringing field at $z=140$ $\mathrm{cm}$ is also shown in Figure 3, where the level zero trigger counter photomultipliers are mounted.

\subsection{EF alone (Run EF051492)}

The geometry of the EF toroid is shown in Figure 9, where the SAMUS toroid is also shown. The EF toroid has coils only on both side yokes, while the SAMUS toroid has coils only on the top and bottom yokes. Calculations for EF alone were performed first to understand the interaction between EF and SAMUS. The EF and SAMUS system will be examined later.

The full cross section of the EF toroid was modeled, including the 12" dia. main ring hole, and 1 " thick 10" o.d. iron shield pipe placed at the nominal position $(x=-0.3297 \mathrm{~m}, \mathrm{y}=2.0691 \mathrm{~m})$.

\subsubsection{Calculation}

Flux calculations for EF alone were performed using the B-H curve presented in Table 1. The flux distribution in EF alone at the nominal current of $2500 \mathrm{~A}$ is shown in Figure 10, where the actual values inside EF are shown. The average field 
values in the top, bottom, and the side yokes are $18.8,18.4$, and $18.5 \mathrm{kG}$. The disturbance created by the presence of the main ring hole is clearly seen. The iron immediately above and below the hole is more saturated than elsewhere.

\subsubsection{Measurement}

The measured B value inside the side yoke was determined to be $19.43 \mathrm{kG}[6]$, which is about $5 \%$ higher than the calculated value.

\subsection{SAMUS alone (Run SA050792)}

The geometry of the SAMUS toroid is shown in Figure 9. It has two unit coils of 25 turns each, which are wound on the top and bottom yokes. These coils are covered with $1 \mathrm{~cm}$ thick steel plates.

\subsubsection{Calculation}

Calculations for the SAMUS toroid alone were performed using the B-H curve in Table III. To take advantage of the symmetry, only the first quadrant of the crosssection was modeled. The flux distribution corresponding to a $1000 \mathrm{~A}$ excitation current is shown in Figure 11, where the flux densities just inside the steel are shown. The flux density in the side yoke is $18.97 \mathrm{kG}$ and very uniform. In the top yoke, it varies from 19.84 to $19.78 \mathrm{kG}$. The $1-\mathrm{cm}$ thick steel coil cover plates are saturated at $20 \mathrm{kG}$ in the opposite direction. The widths of the side and top yokes are 55.9 and $57.2 \mathrm{~cm}$.

The fringing field inside the hole (in the first quadrant) is shown in Figure 12. The calculated field values along the inside surface are shown together with the measured values in brackets [3]. The agreement is fairly good, considering that the calculations are two-dimensional.

\subsubsection{Measurement}

The measured flux densities in the top and side yokes are 18.8 and $17.7 \mathrm{kG}$ [7]. these values are roughly $1 \mathrm{kG}(-5 \%)$ lower than the calculated values.

\subsection{EF and SAMUS (EFSA041092)}

The EF-SAMUS system geometry is shown in Figure 9. In this calculation the main ring beam hole in EF is included, and located off the center line as designed. In order to include the effect of the off-center main ring hole in EF, it was necessary to model the complete cross section.

\subsubsection{Calculation}


The B-H curve from Table I was used for EF and that from Table III for SAMUS. The nominal operation current are respectively $2500 \mathrm{~A}$ for EF and $1000 \mathrm{~A}$ for SAMUS, with both currents set to produce the same flux flow direction.

The calculated flux distribution inside the EF yoke is shown in Figure 13. where the flux density just inside the steel is shown. Due to the interaction with SAMUS toroid, the side yokes of EF have higher flux values of about $19.1 \mathrm{kG}$. The top and bottom yokes of EF have lower values of about 18.2 and $17.7 \mathrm{kG}$ respectively. The flux distribution inside EF is quite redistributed compared to the case of EF alone. The fringing field value just under the EF toroid is $127 \mathrm{G}$ in this 2-D calculation.

The flux distribution inside the SAMUS yoke is significantly perturbed by the EF toroid, as is shown in Figure 14. The top and the bottom yokes are highly saturated, while the side yokes are not saturated. The flux density inside the top yoke is $21.1 \mathrm{kG}$ and the bottom yoke is showing $21.0 \mathrm{kG}$. The left-side vertical yoke, which is closer to the main ring hole has about $14.8 \mathrm{kG}$ and the right-side vertical yoke has about $14.6 \mathrm{kG}$. This asymmetry is due to the main ring hole. The flux distribution inside the cover plates for the SAMUS coils are in the opposite direction and not highly saturated.

The fringing field distribution inside the SAMUS hole is shown in Fig. 15. The field value at the center of the hole is $27 \mathrm{G}$, pointing to the left. This is due to the bottom coil cover being more saturated than the top one. At the median surfaces of the side yokes, the fringing field values are about $40 \mathrm{G}$.

The flux distribution around the 12" main ring hole with 1 " thick 10 " o.d. iron magnetic shield, is shown in Fig. 16. The magnetic flux around the main ring hole in $\mathrm{EF}$ is quite distorted. The calculated field value at the center of the hole is $54 \mathrm{G}$ without any more magnetic shielding for the vacuum pipe, and the flux value inside the iron shield ring is $19.8 \mathrm{kG}$ at the top and bottom of the ring.

\subsubsection{Measurement}

The flux measurement on the EF and SAMUS system with the same flux flow direction was done and reported [8]. The flux densities in the top and side yokes of EF are estimated 18.4 and $19.6 \mathrm{kG}$ respectively. The values in the top and side yokes of the SAMUS are estimated 19.9 and $15.6 \mathrm{kG}$ respectively.

Inside the SAMUS hole we measured the vertical components of the fringing field at $x=+24$, and $-24 \mathrm{~cm}, y=0$. They were about +50 , and $-50 \mathrm{G}$ respectively, while the calculated value is about $40 \mathrm{G}$. The measured fringing field at the bottom center of EF was $70 \mathrm{G}$, while the 2-D calculated value neglecting the effect of the platform is $127 \mathrm{G}$, which is a little higher probably due to the 2-dimensional calculation. 
The residual field inside the main ring vacuum pipe with additional magnetic shield, placed inside the main ring hole with $1 "$ thick shield in EF, was measured to be about $0.1 \mathrm{G}[9]$.

\section{3-DIMENSIONAL FIELD CALCULATION}

All three-dimensional calculations were performed using TOSCA version 6.1, a well-known finite element magnetostatics code [4]. Two cases were analyzed. In the first case, the CF and EF toroids and the supporting structure were modeled [10]. In the second case, the SAMUS toroid was added. The air gaps in CF were not included in the geometry because of their very small relative dimensions; however, the B-H curve was modified in the second case to take into account effect of the gaps on the reluctance of the CF toroid. The B-H curve for CF is shown in Table II. The B-H curves for EF and SAMUS are the same ones as for 2-D case. The main ring hole in EF was not included because of its small relative size and because its presence would have broken the left-right symmetry of the model. The preliminary data of the second case with preliminary B-H curves was reported elsewhere [11].

To minimize the size of the problem, all symmetries were exploited and a problem region representing one fourth of the total detector volume was used. The problems were solved using approximately 90,000 nodes and quadratic interpolation on a Solbourne Series 5/801 workstation (roughly equivalent to a Sun SparcStation II).

The TOSCA algorithm is based on a scalar potential formulation and requires the contribution of the coils to the total field to be calculated separately by numerical integration. The D0 detector has a total of 36 coils, 5 yoke structure and a steel platform. A typical run took about three days, most of the time being used to calculate the coil contribution.

Due to the coarseness of the discretization, the field in the corner regions of the $\mathrm{EF}$ and $\mathrm{CF}$ toroids exhibits small fluctuations and an unexpected dip in magnitude exactly on the corner bisector.

In the final calculation, the flux density in $\mathrm{CF}$ is $19.4 \mathrm{kG}$ in the top gap, which is in agreement with the measured value of $19.2 \mathrm{kG}$. The results show $18.5 \mathrm{kG}$ at the top of its vertical yoke, reflecting $3.2 \%$ wider yoke width. The B-value in the central beam is $17.5 \mathrm{kG}$, reflecting $10 \%$ wider yoke width and some leakage into the fringing field and into the platform.

The calculated $\mathrm{B}$ values in EF are 18.39 and $17.62 \mathrm{kG}$ in the top and bottom yoke, and $20.12 \mathrm{kG}$ in both side yokes. There is no main ring beam pipe hole in EF, and no left and right asymmetry. The fringing field under the bottom center is $114 \mathrm{G}$, while the measured value is $70 . \mathrm{G}$. 
The calculated B values in the inserted SAMUS are 21.02 and $20.86 \mathrm{kG}$ in the top and bottom yoke, and $15.46 \mathrm{kG}$ in both side yokes. These values are reflecting the interaction of the EF and SAMUS coils to the yoke of the other member.

\section{OVERALL COMPARISON BETWEEN CALCULATED AND MEASURED VALUES}

The typical field values, measured and calculated, with the CF, EF and SAMUS toroids are summarized and shown in Table IV. For both EF and CF, the calculated and measured flux values are within $2 \%$ in both calculation methods. For SAMUS, the calculations and measurements agree within $5 \%$.

A summary of the calculation results for EF alone and SAMUS alone is presented in Table V.

\section{FIELD MAPPING DATA}

The field map used for Monte Carlo calculation was obtained from twodimensional calculations using ANSYS. For CF and EF, the field was mapped on a $10-\mathrm{cm}$ square grid, using cell values at $5,15,25 \mathrm{~cm}$ etc. A finer $5-\mathrm{cm}$ square grid is used for the SAMUS toroid region.

To make the $10 \mathrm{~cm}$ or $5 \mathrm{~cm}$ grid for CF, EF and SAMUS, the result of an irregular mesh ANSYS calculation was used as the starting point, and the grid was calculated using the technique of submodelling with one cycle of iteration.

The resulting field maps reproduce the actual field distribution fairly well, except the areas around the SAMUS coils and the main ring hole in EF.

\section{Acknowledgments}

We would like to thank Mr. R. Wands for stimulating discussions and help with the ANSYS program.

\section{Appendix}

With the forward current setting of both power supplies, the magnetic flux in $\mathrm{CF}$, both EF's and both SAMUS's circulates in the counter-clockwise direction, looking at the detector from the north (same as the direction of proton beams). For historical reasons, the reading of all Hall probes is set in negative under these conditions. 


\section{References}

1. R. Yamada et. al., "Magnetic Characteristics of the D0 Detector". To be published in Proceeding of the 12th Int. Conf. on Magnet Tech., Leningrad, USSR, 1991.

2. R. Yamada and P. Lee, "Magnetic Field Calculation of CF Toroid". D0 Note No. 833, 1989.

3. K. Hodel and R. Yamada, "Magnetic Field Calculation of SAMUS and EF Toroids". D0 Note No. 1000, 1990.

4. J. Simkin and C. W. Trowbridge, "Three-dimensional Nonlinear Electromagnetic Field Computations, using Scalar Potentials", IEEE Proc., 127, 6, 368-374, 1980.

5. R. Yamada et. al., "Magnetic Field Monitor System for D0 Toroids". D0 Note. No. $1410,1992$.

6. H. Jostlein, "D0 Toroid Field Measurements from April 19, 1989". D0 Note No. $846,1989$.

7. H. Jostlein and S. Chekulaev, "June 1990 Field Measurements on SAMUS Toroids on the side walk" D0 Note 1036, 1990.

8. H. Jostlein, "D0 EFN/SamusN Toroid Field Measurements of December 15, 1990". To be issued in D0 Note.

9. H. Jostlein, "Main Ring Pipe Stray Field inside EF Iron at D0". D0 note 1358. 1992.

10. J-F. Ostiguy and R. Yamada, "Three-Dimensional Field Map of the Fermilab D0 Detector". Proceeding of 1991 National Accelerator Conf. p.2131, San Francisco.

11. A. Mesin et. al., "2-D and 3-D Display and Plotting of 3-D Magnetic Field Calculation for D0 Detector. D0 Note No.1285. 1991. 
Table I

$B$ vs $H$ for CF \& EF

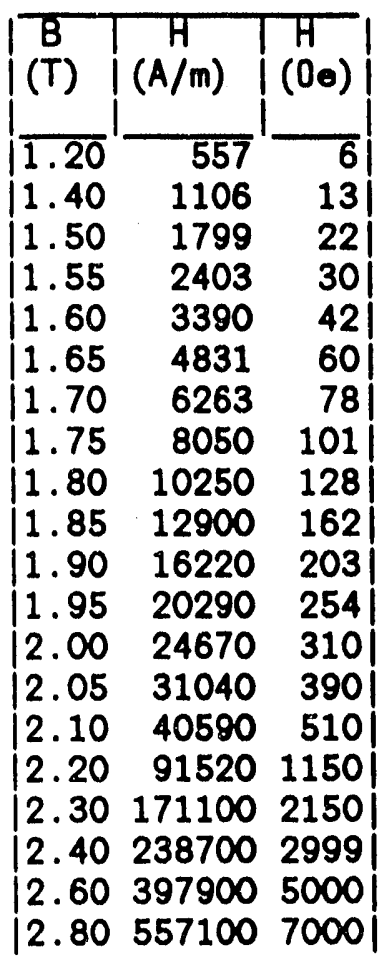

Table II

$B$ vs $H$ Modified for CF of Tosca

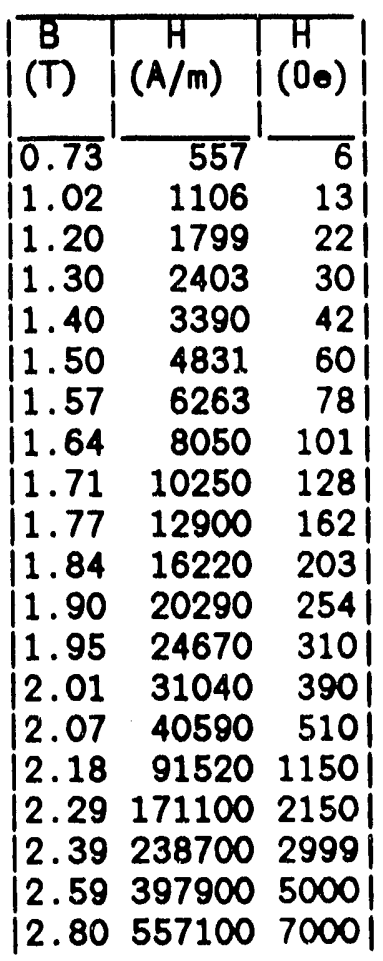

Table III

$B$ vs $H$ for SAMUS

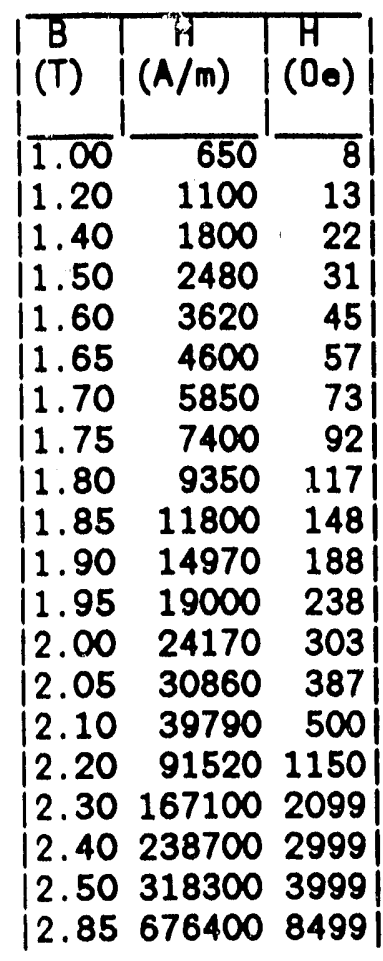


Table IV Flux Distribution in D0 Toroids

The CF and EF's are excited with $2500 \mathrm{~A}$, and the SAMUS's are excited with $1000 \mathrm{~A}$. All toroids are in the same flux orientation.

\begin{tabular}{|c|c|c|c|c|c|}
\hline Toroid & Position & $\begin{array}{l}\text { Measured } \\
\text { B (kG) }\end{array}$ & $\begin{array}{l}\text { ANSYS } \\
\text { B (kG) }\end{array}$ & $\begin{array}{c}\text { TOSCA } \\
\text { B (kG) }\end{array}$ & Measured Data Ref \\
\hline To & $\begin{array}{l}\text { Top gap } \\
\text { op of vert. yoke } \\
\text { Side yoke } \\
\text { Bottom yoke } \\
\text { Central beam }\end{array}$ & $\begin{array}{l}19.2 \\
18.4\end{array}$ & $\begin{array}{r}19.34 \\
18.67 \\
19.11 \\
19.51 \\
18.68\end{array}$ & $\begin{array}{l}19.41 \\
18.54 \\
18.55 \\
18.62 \\
17.48\end{array}$ & Ref.6 \\
\hline $\mathrm{EF}$ & $\begin{array}{l}\text { Top yoke } \\
\text { Bottom yoke } \\
\text { Side yoke }\end{array}$ & $\begin{array}{l}18.4 \\
19.6\end{array}$ & $\begin{array}{l}18.2 \\
17.7 \\
19.1\end{array}$ & $\begin{array}{c}\text { No M.R. } \\
18.39 \\
17.62 \\
20.12\end{array}$ & $\begin{array}{l}\text { Ref. } 8 \\
\text { Ref. } 8\end{array}$ \\
\hline SAMUS & $\begin{array}{l}\text { Top yoke } \\
\text { Bottom yoke } \\
\text { Side yoke }\end{array}$ & $\begin{array}{l}19.9 \\
15.6\end{array}$ & $\begin{array}{l}21.1 \\
21.0 \\
14.8\end{array}$ & $\begin{array}{l}21.02 \\
20.86 \\
15.46\end{array}$ & $\begin{array}{l}\text { Ref.8 } \\
\text { Ref. } 8\end{array}$ \\
\hline
\end{tabular}

Table V Data Summary for EF alone and SAMUS alone

EF alone

Top yoke

Bottom yoke

Side yoke

19.43
18.8

18.4

18.5
Ref. 6

SAMUS alone

$\begin{array}{llll}\text { Top yoke } & 18.8 & 19.8 & \text { Ref. 7 } \\ \text { Side yoke } & 17.7 & 19.0 & \end{array}$




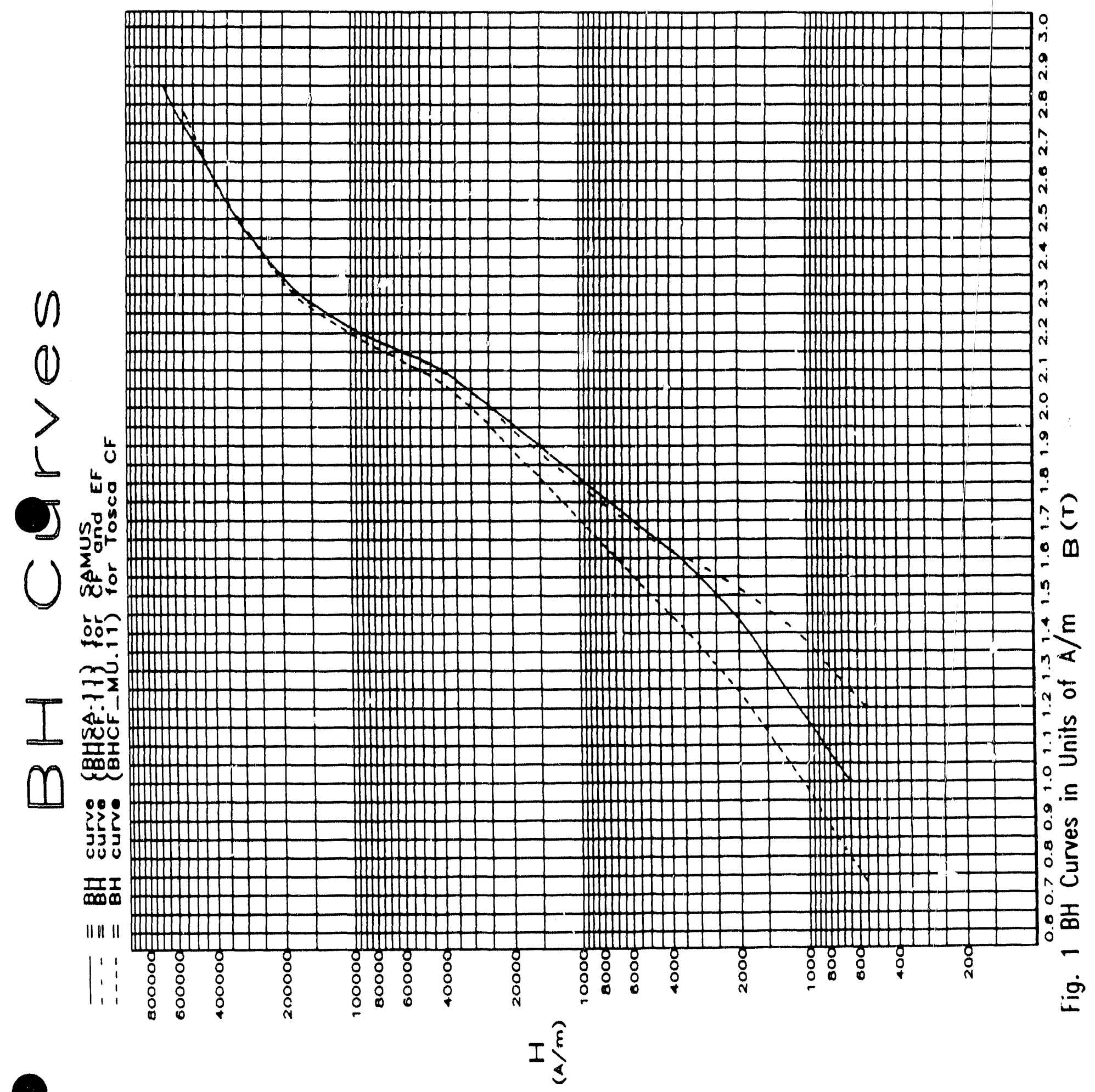




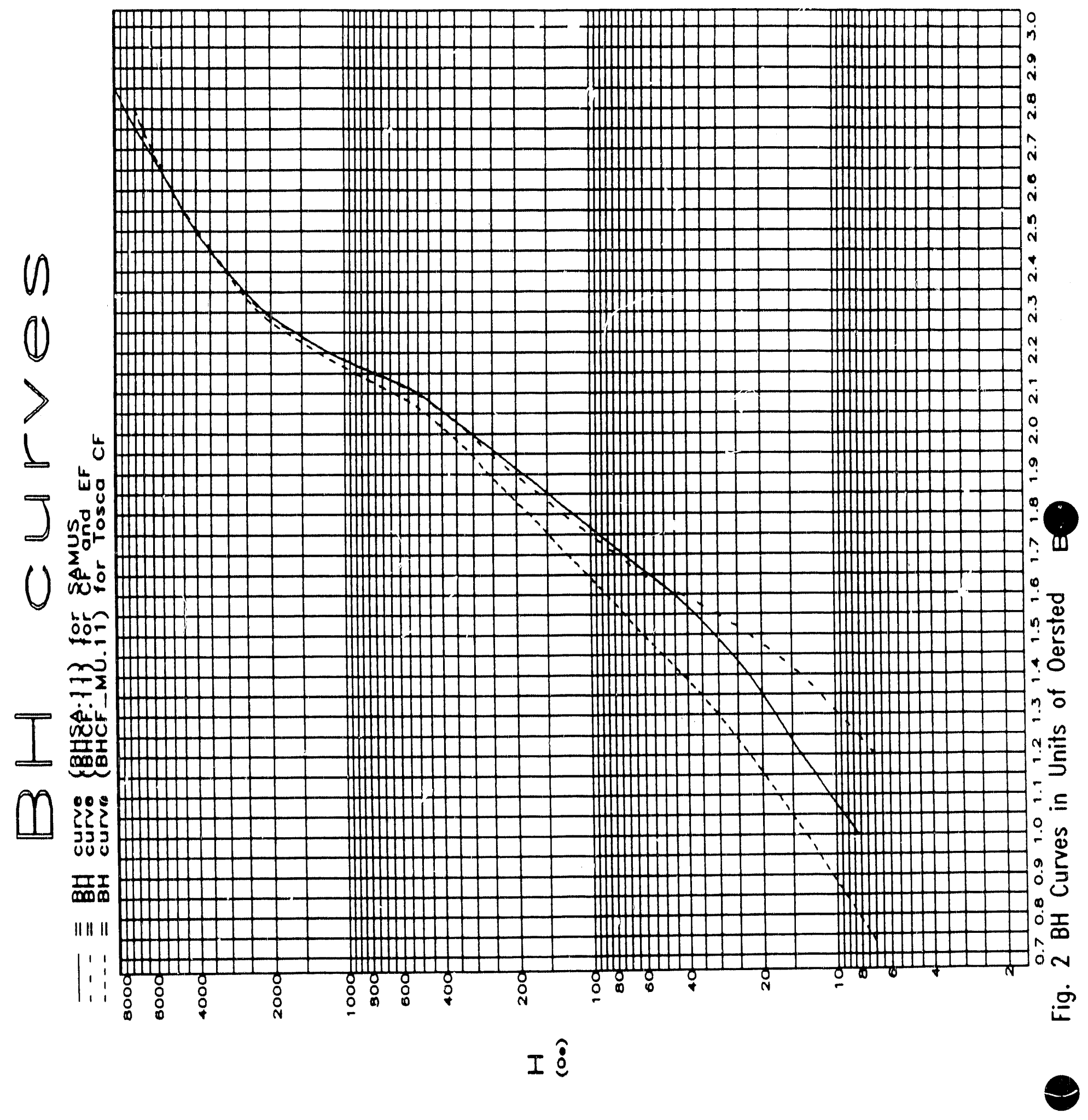


Fig. 3 Geometry of CF Toroid

Colculated Flux Volues(in KG) in CF Yoke Avereged Across its Width(in cm) \& Meosured Fringing Field inside CF ot $Z=140 \mathrm{~cm}$ (in Gouss)

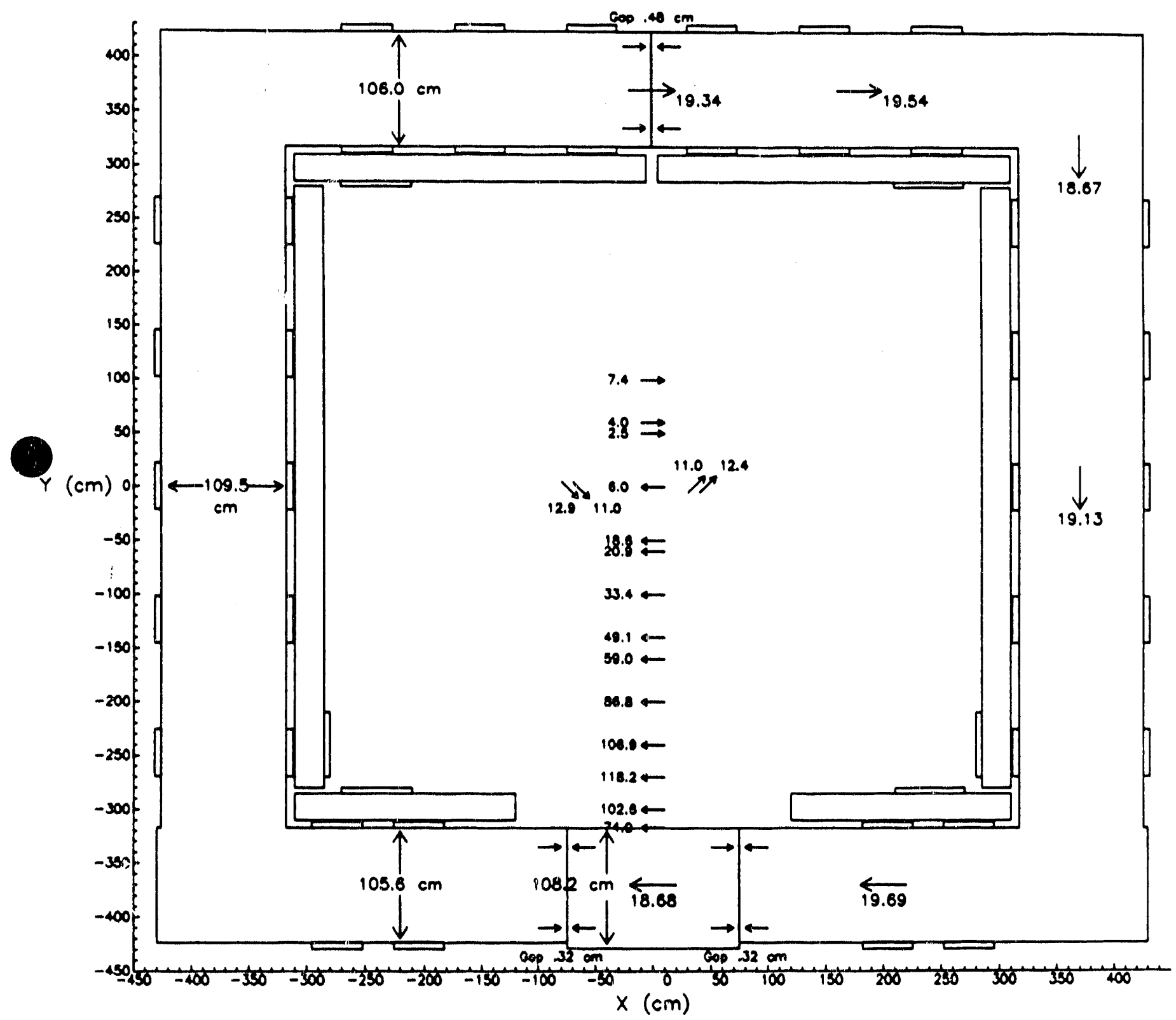




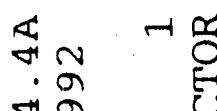

सबे

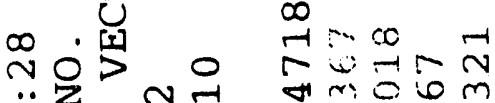

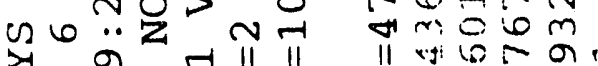

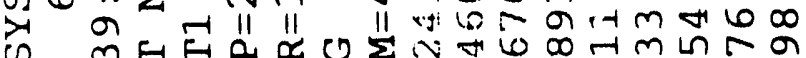

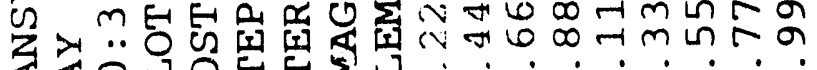

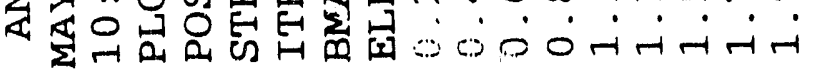

กิ

$N+\cdot 0$

. 00

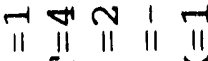

हn

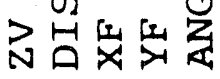

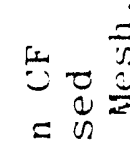

$\because-\stackrel{0}{=}$

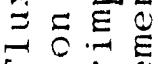

T I.

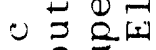

b 0

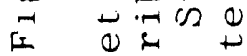

$\sum_{60}^{1}$ 出 $\frac{1}{4}$

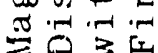

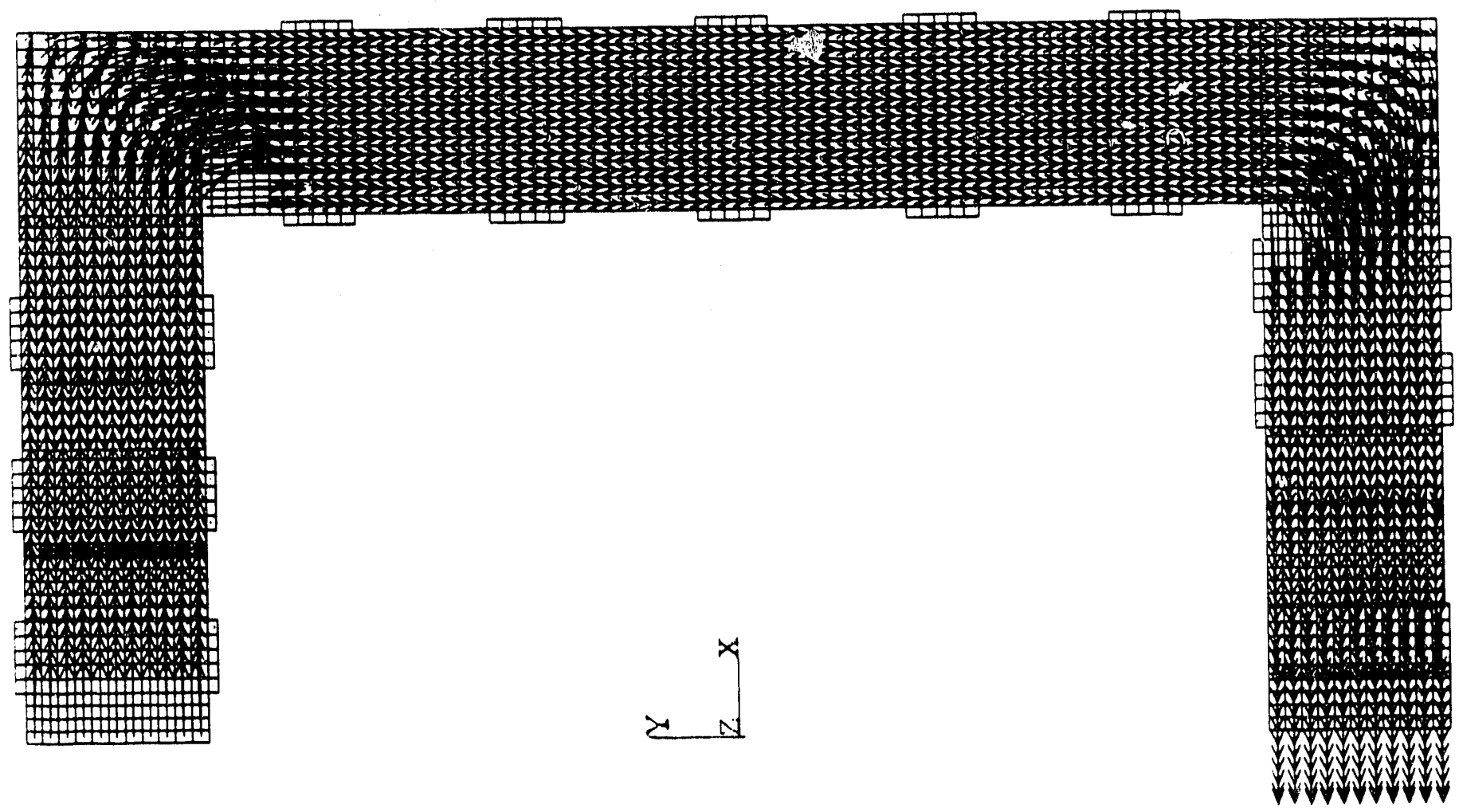

品

पु 

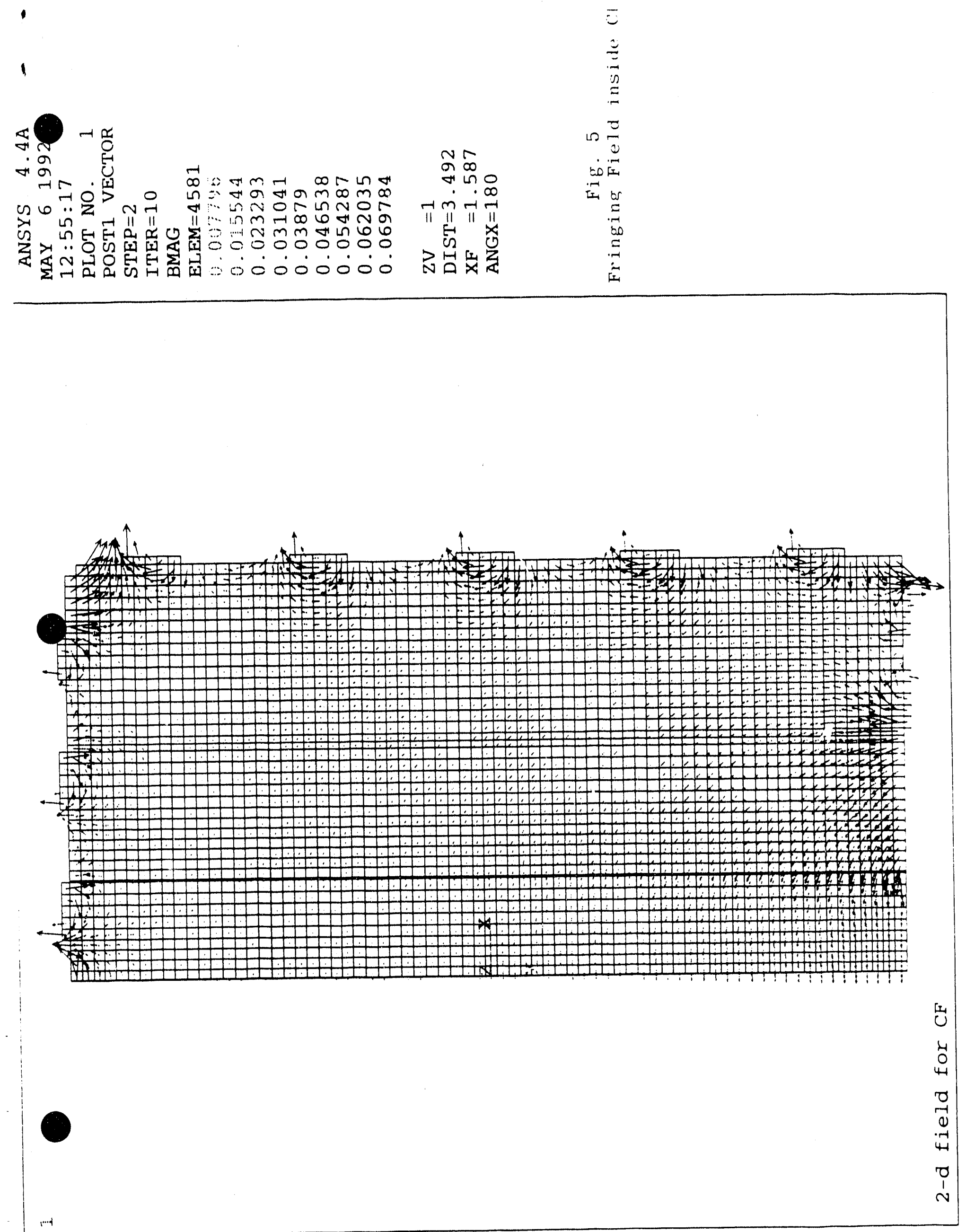


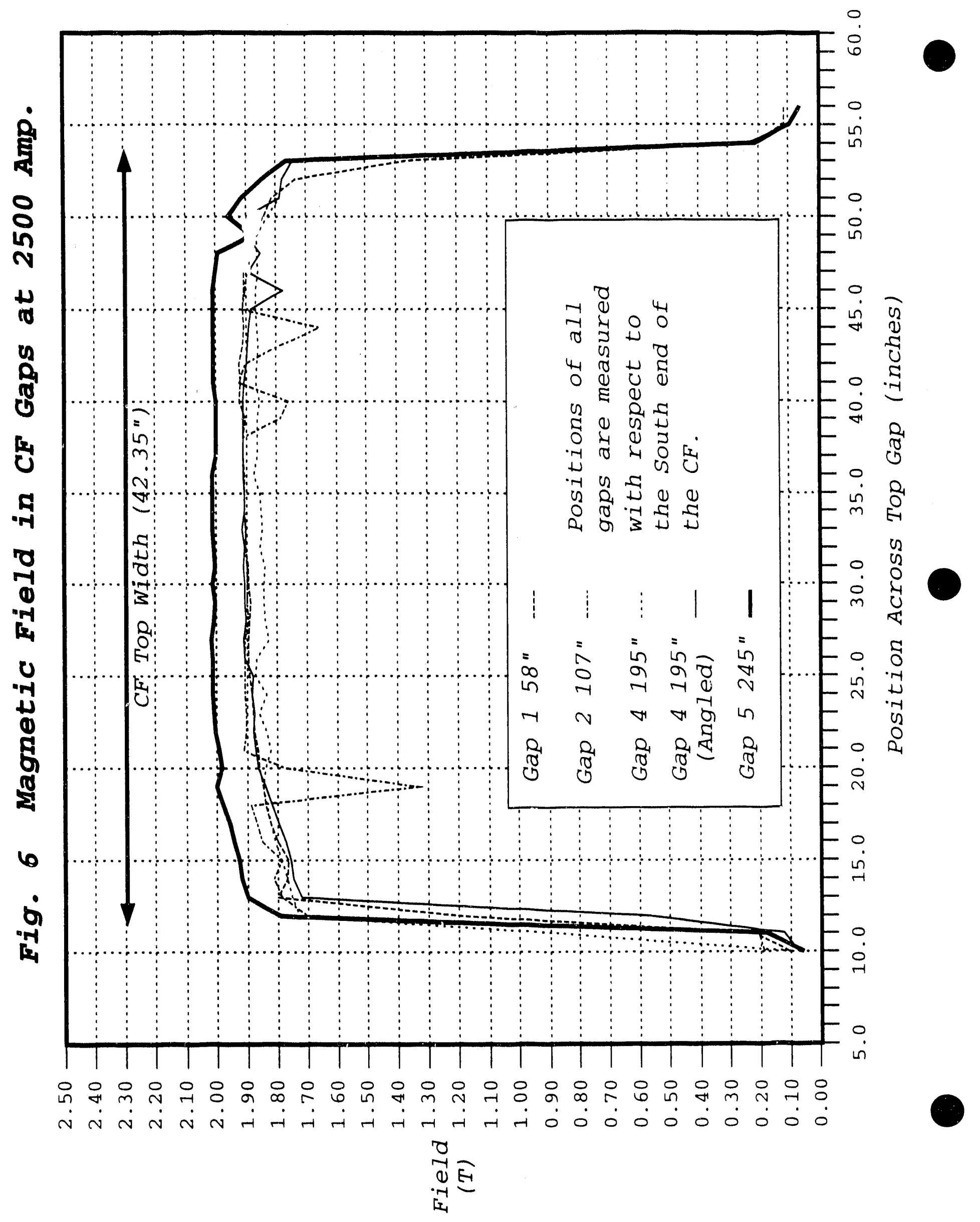




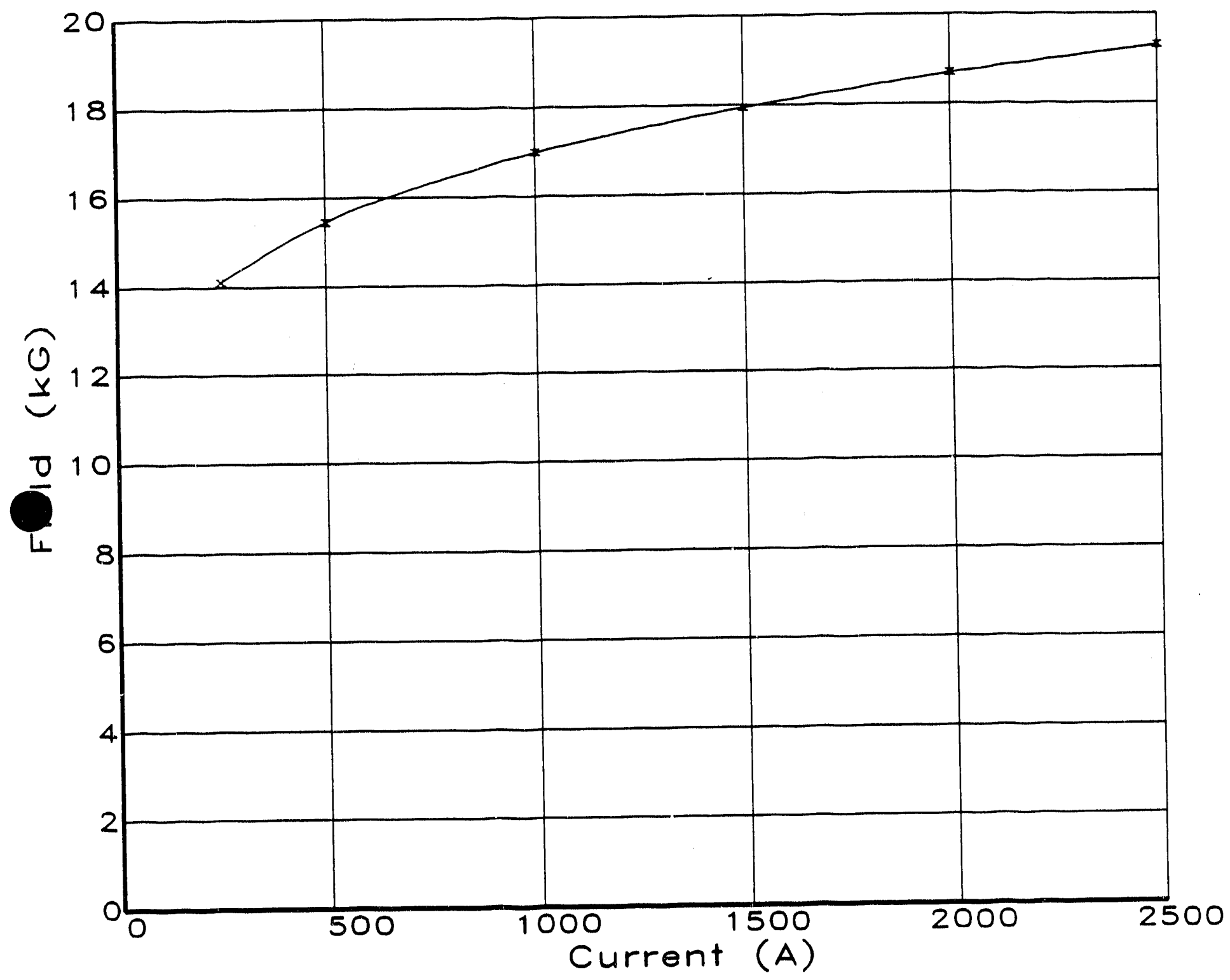

Fig. 7 Excitation Curve of CF measured in Top Gap 


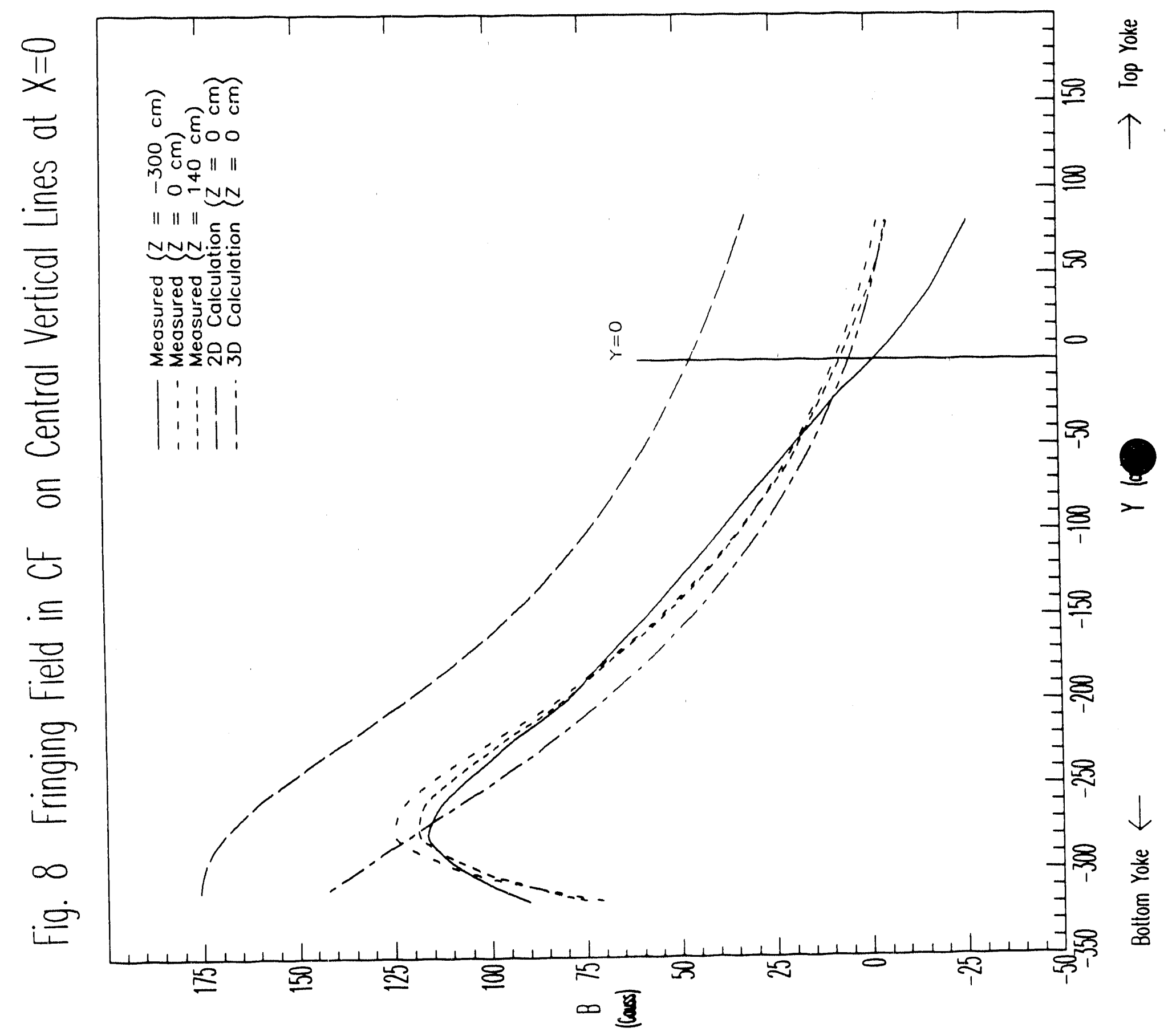




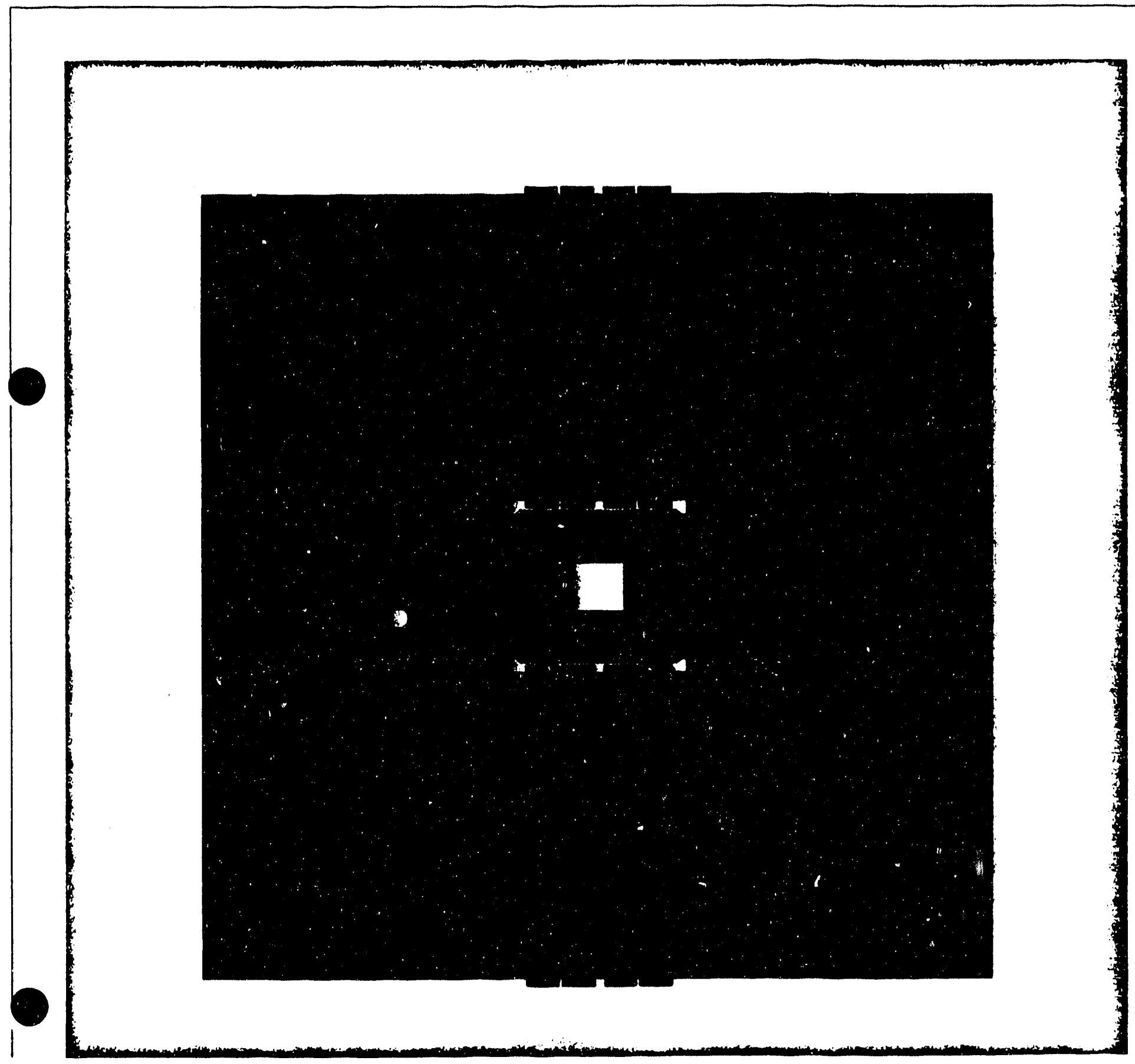



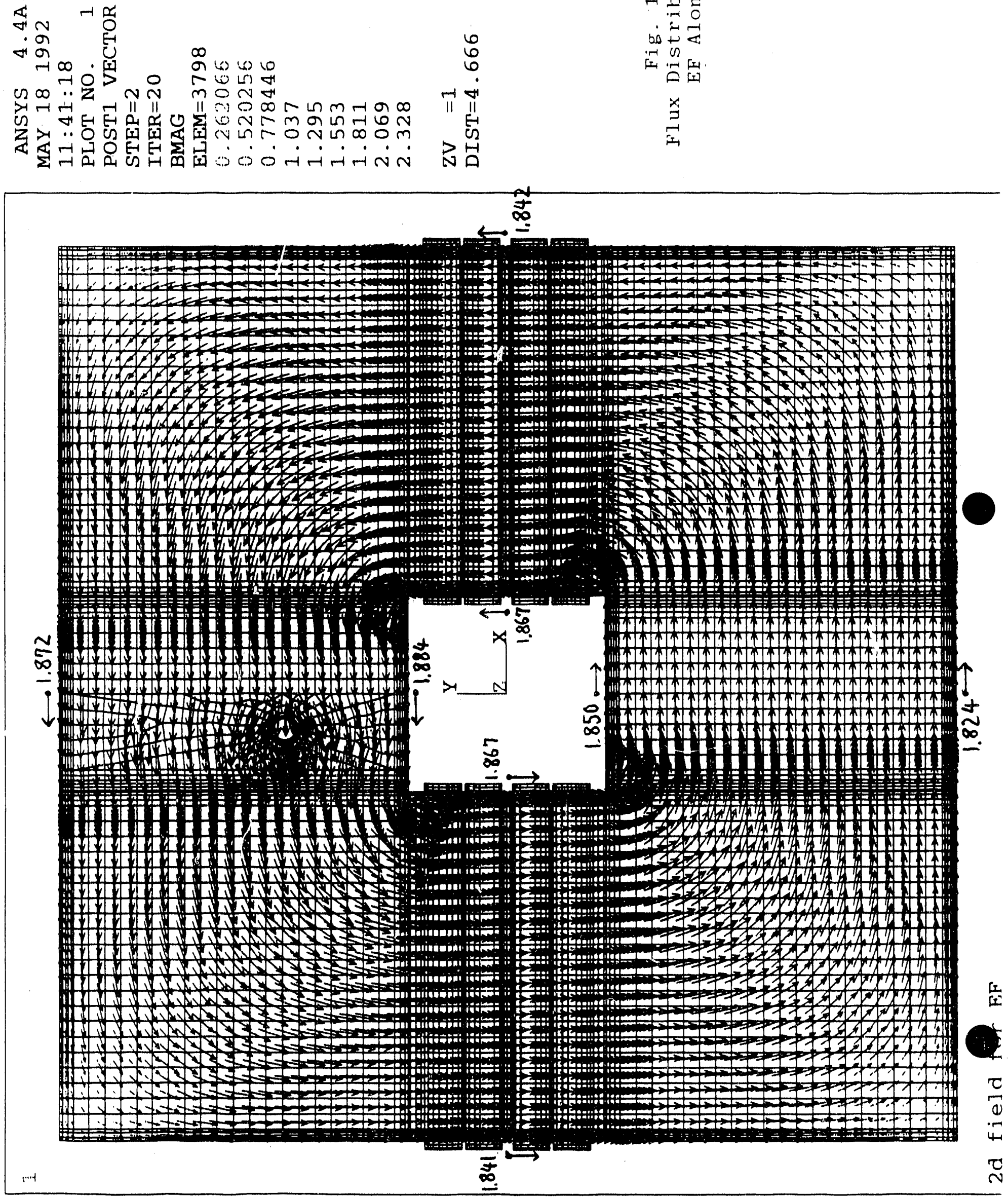


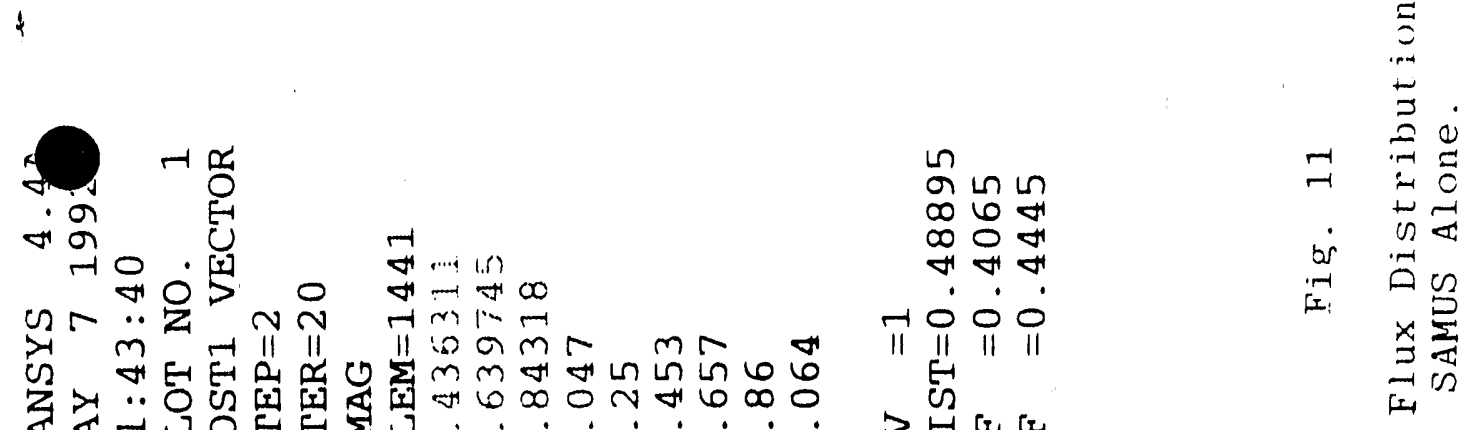

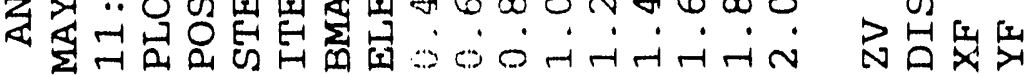

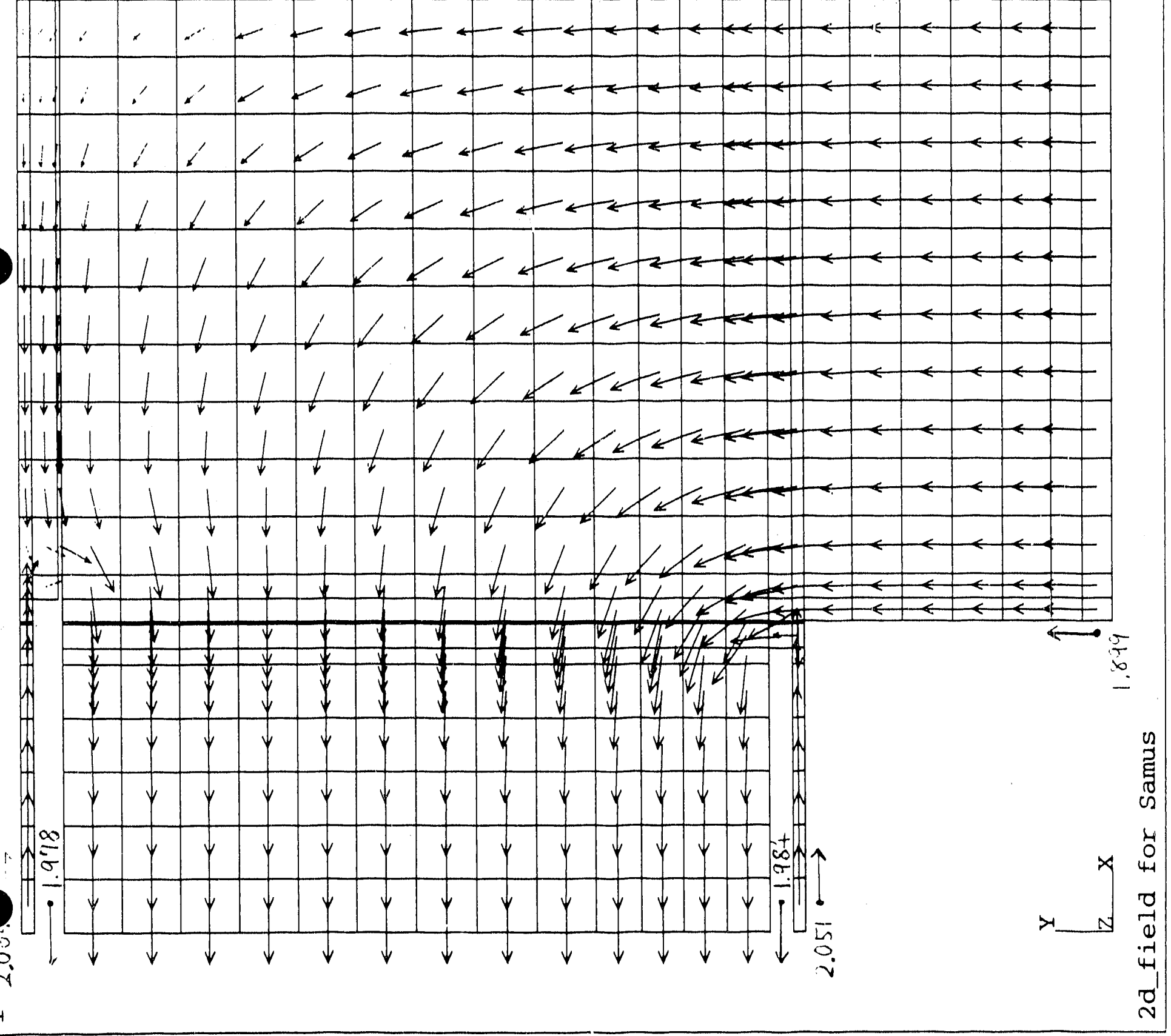


H $N$ N मू के है

กอ่ यกㄴ N N

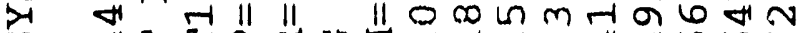

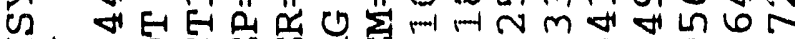

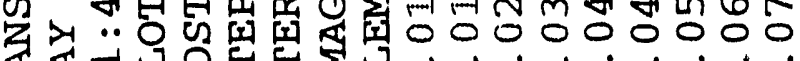

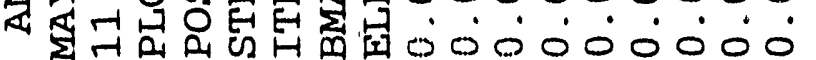

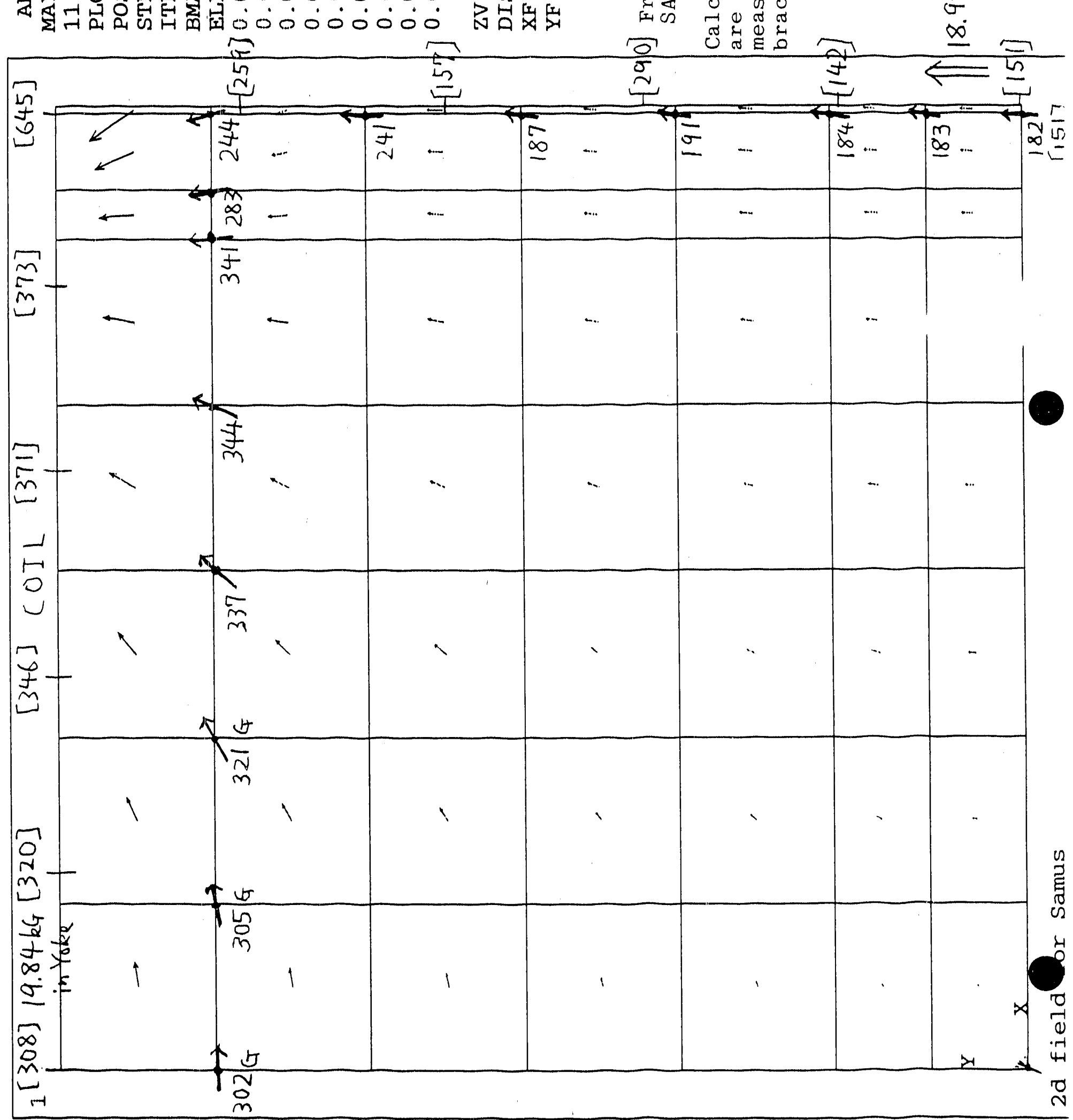




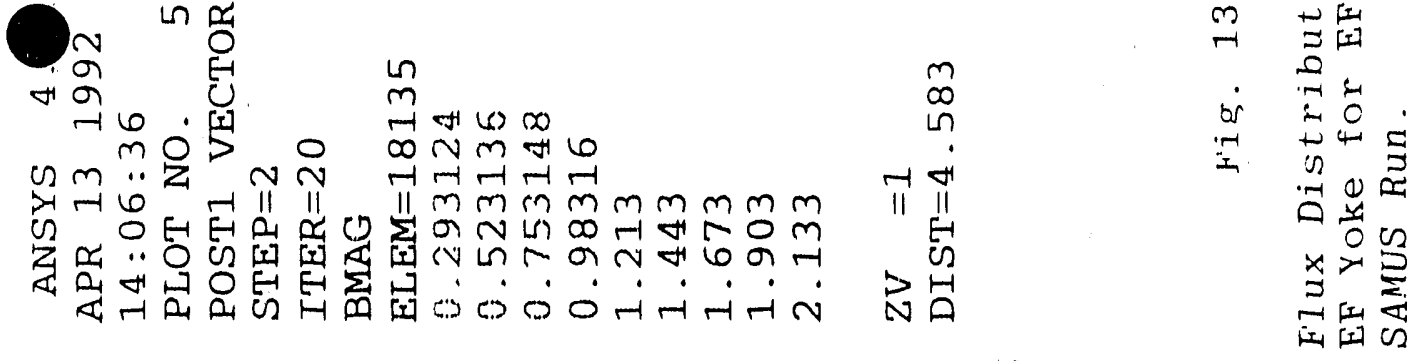

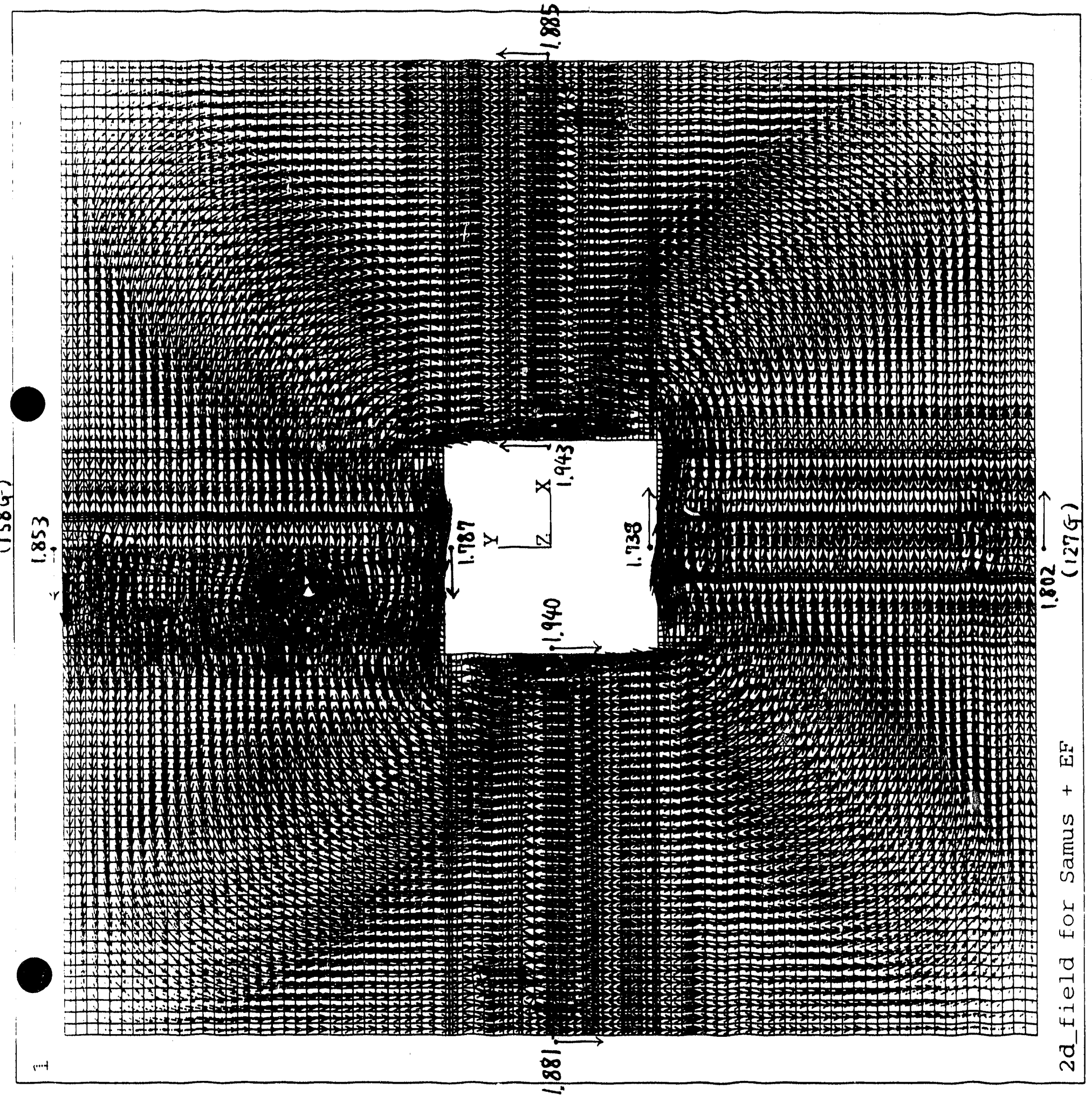




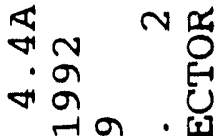

तथ

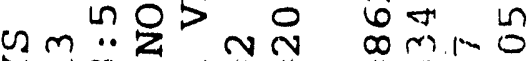

>

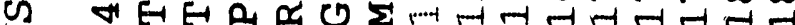

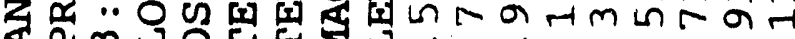

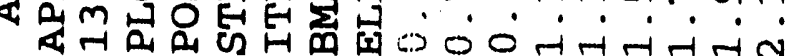

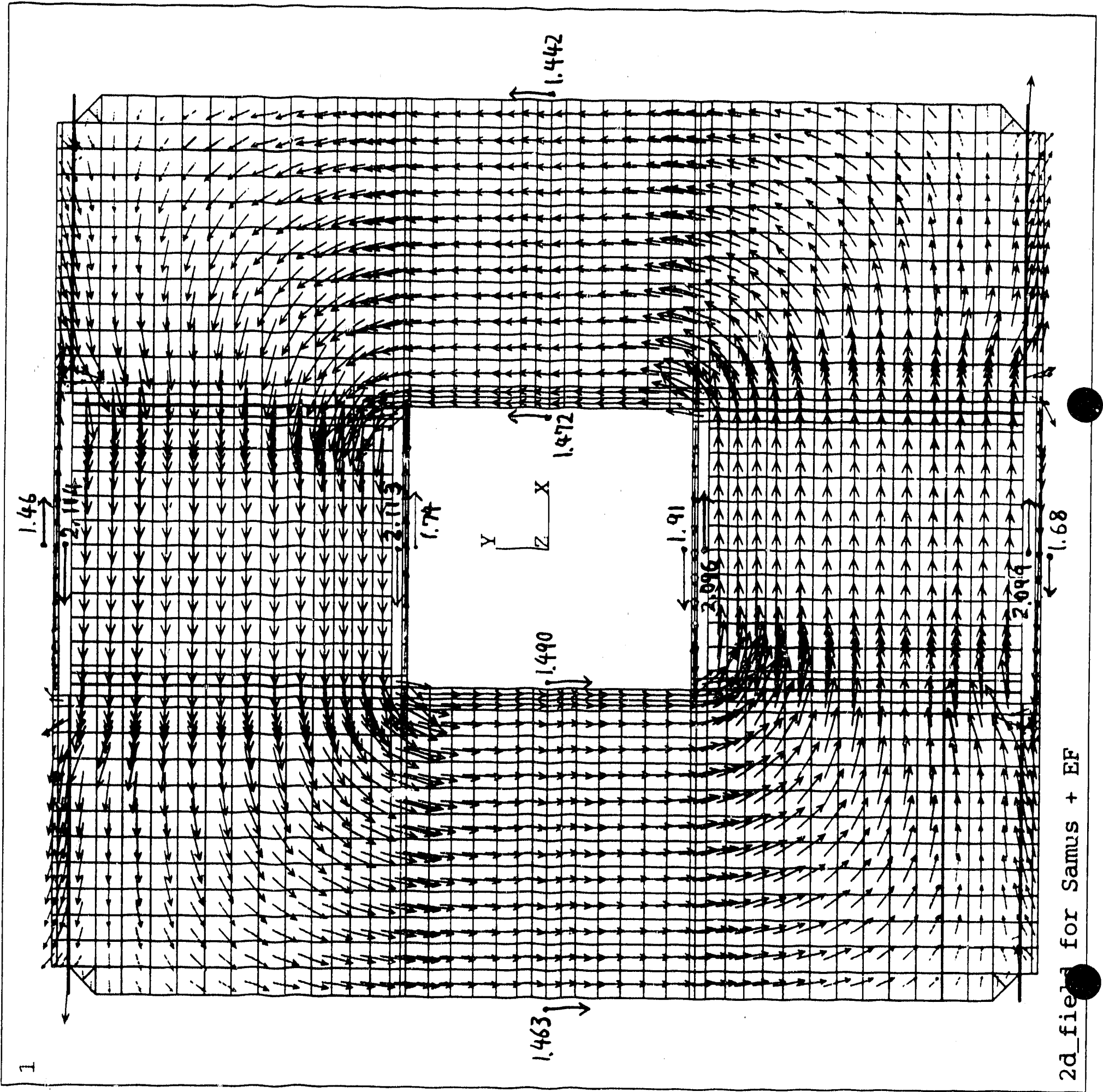


$m$ m ni...i. $\infty$ in

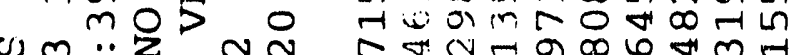

ग्रन

⿹

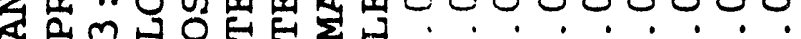

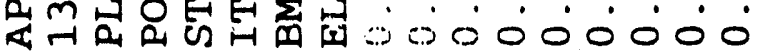

\begin{tabular}{|c|c|}
\hline ă & $\stackrel{10}{7}$ \\
\hline ? & bo \\
\hline 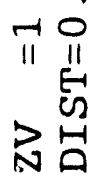 & $\vec{I}$ \\
\hline
\end{tabular}

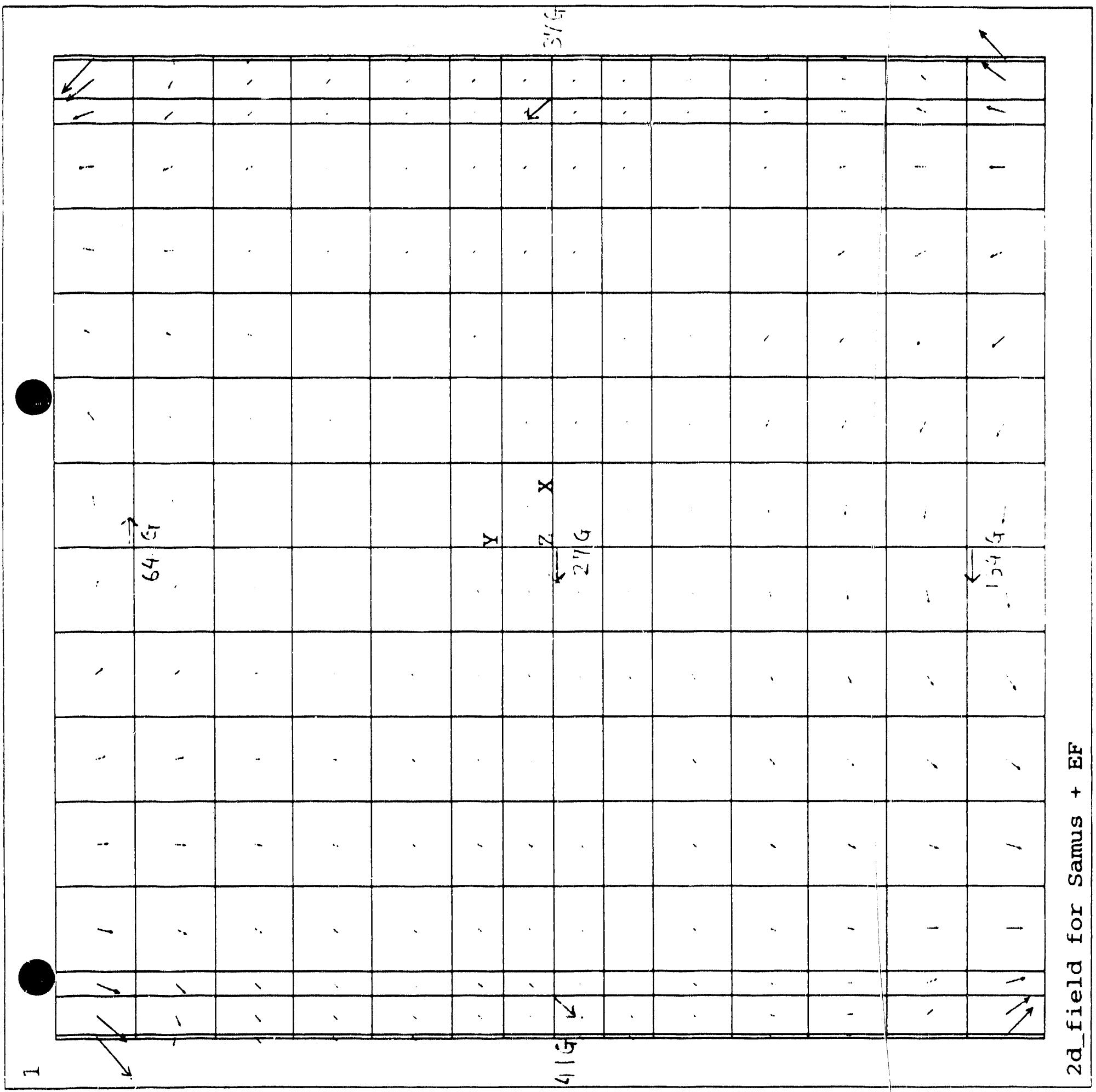




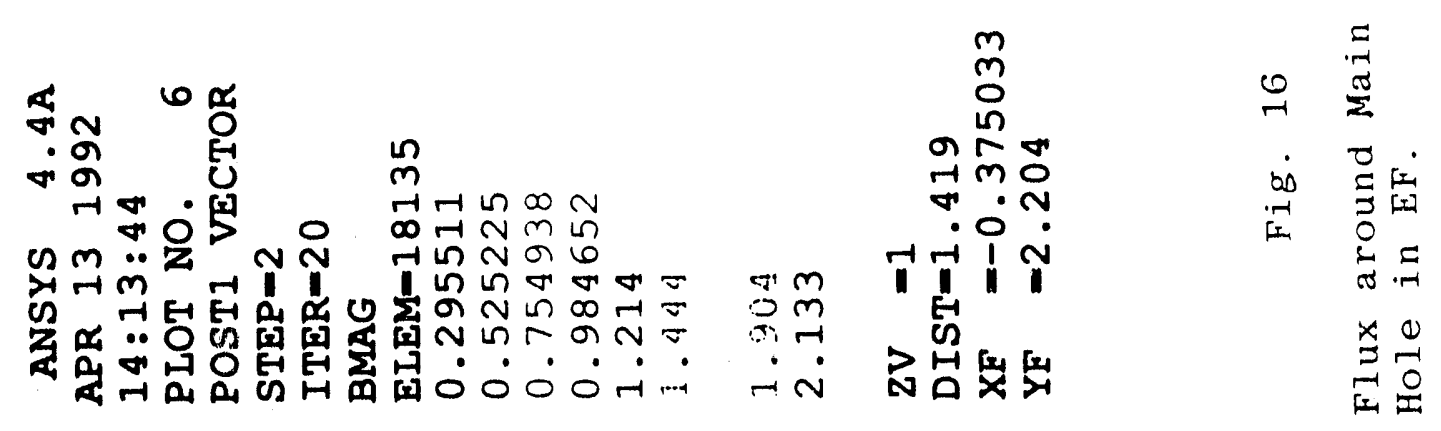

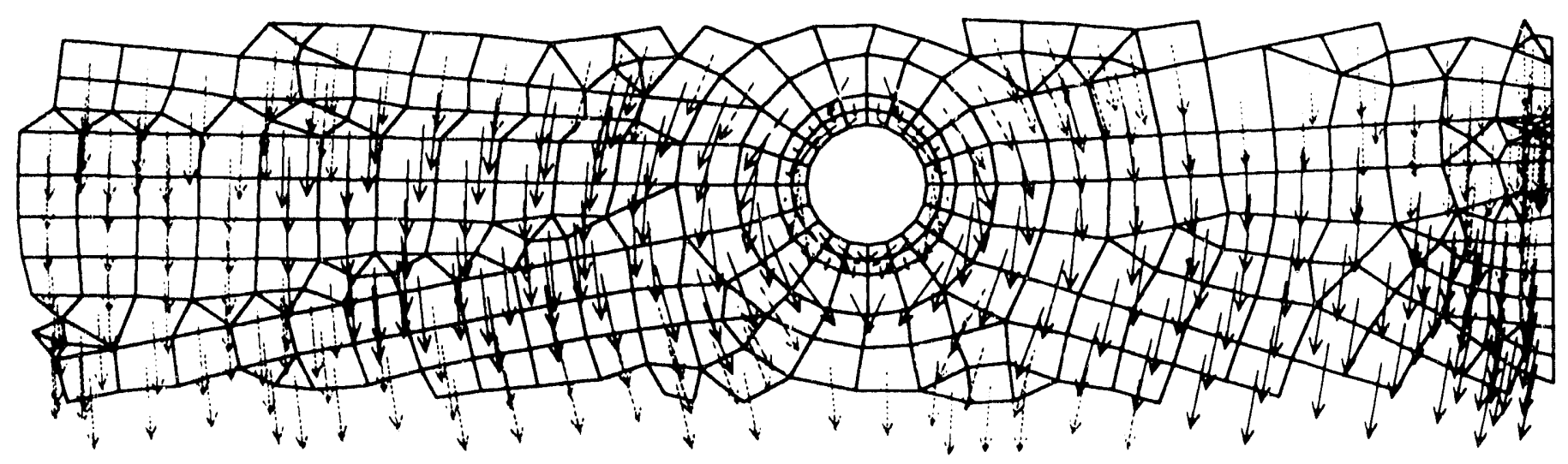



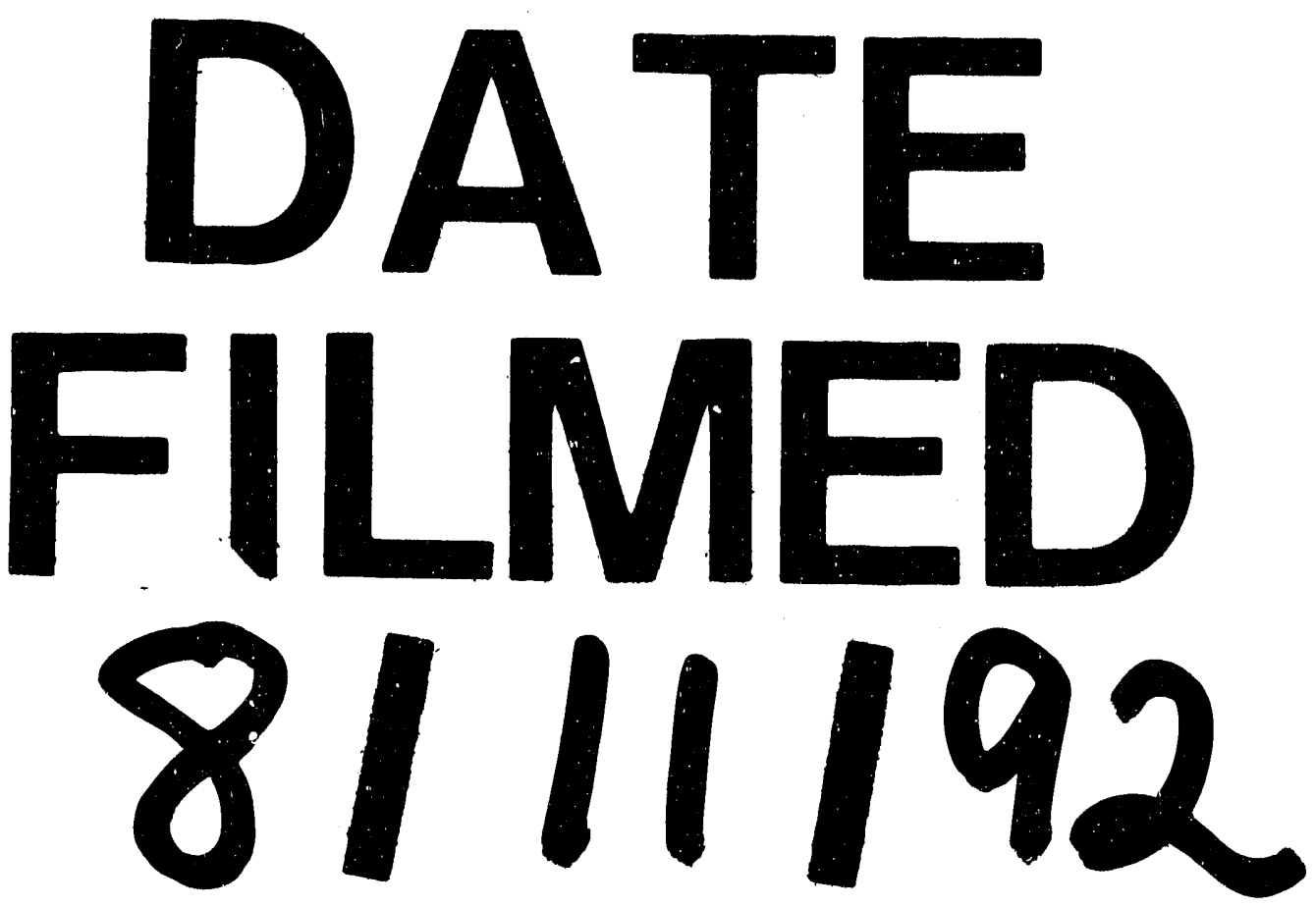
